\title{
Editorial 2010
}

\section{J. W. Foppe van Mil}

Published online: 3 December 2009

(C) Springer Science+Business Media B.V. 2009

Dear Reader,

Times are changing and so is the work around our journal. We are honoured to receive an ever increasing amount of papers that deal with clinical pharmacy and pharmaceutical care from all over the world, and especially Europe. As editor-in-chief I also value the support of both the Dutch Pharmaceutical Association, KNMP, and the European Society of Clinical Pharmacy (ESCP). We regularly publish the abstracts of the ESCP symposia on our Springerlink website and in the paper edition of our journal.

As for ESCP, that association has gone through a very difficult period but is now firmly in control again.

A couple of years ago, ESCP decided that they would like to professionalise their office and educational activities, and moved into the offices of a larger organisation in Brussels. But after a couple of years it became apparent that this move was not so wise as it initially seemed. For a relatively small organisation like ESCP, an external professional office simply proved to be too expensive. Luckily the board stepped in just in time, and decided to move the office out of this larger organisation again. The (voluntary) ESCP secretary then started manning the office himself and 'for free'. This led to an organisation that now is healthy again, both in organisational terms as well as financially.

I think that two people, Gert Laekeman (from Leuven, Belgium) and Erik Gerbrands (from Buitenpost, the Netherlands), should receive a special thank you for this! Both just stepped down from the ESCP board. If they would not have invested so much time and energy, Europe would not have a Clinical Pharmacy Society anymore. And judging by the current level of research, and valuable articles that are being published by European clinical pharmacy practitioners and researchers in our journal, ESCP does fulfil an important role in European pharmacy.

As editor-in-chief of Pharmacy World \& Science, I do look forward to a further fruitful cooperation with a healthy European Society for Clinical Pharmacy. 